\title{
Феномен справедливости в оплате труда медицинских работников
}

\author{
А.Л. ТЕМНИЦКИЙ*
}

\begin{abstract}
*Александр Лазаревич Темницкий - кандидат социологических наук, доцент, кафедра социологии, Московский государственный университет (институт) международных отношений МИД РФ (МГИМО). Адрес: 119454, Москва, проспект Вернадского, д. 76. E-mail: taleksandr@list.ru
\end{abstract}

Цитирование: Темницкий А.Л. (2017) Феномен справедливости в оплате труда медицинских работников // Мир России. Т. 26. № 3. С. 64-89. DOI: $10.17323 / 1811-038 X-2017-26-3-64-89$

В статье на материалах повторных исследований (2007-2014 г2.) труда медищинских работников бюджетных лечебных учреждений раскрывается роль справедливости в оплате труда по отношению к трудовой мотивации и проводимой политике по внедрению эффективного контракта.

Анализ роста числа обращений исследователей к проблеме сочиильной справедливости в 2000-е годы позволяет утверждать, что ее актуализация со стороны работников вызвана прежде всего ошущением потери связи между размером зарплаты и личным вкладом. В статье обосновываются и эмпирически выявляются признаки патерналистской и либеральной моделей справедливости в оплате труда. Долевая представительность патерналистской модели среди врачей составляет примерно третью часть, а либеральной - пятую часть от числа опрошенных, остальные образуют смешанный тип. Особенностью предлагаемого подхода к изучению справедливости является направленность на обнаружение эмпирических проявлений феномена справедливости вместо общепринятого, а именно изучение представлений о справедливости. Справедливость в оплате труда рассматривается не столько как вид эмочионального чувства, сколько как аналитическая и объясняющая переменная. Специифика феномена справедливости в оплате труда медиичинских работников заключается в противоречивом соотношении роста денежной мотивации в свете эффективного контракта и представлений о статусе врача в обществе, престижности и гуманитарной роли профессии.

1 Автор благодарен профессору С.В. Шишкину за ценные замечания и рекомендации. 
По результатам проведенных исследований выявлена преобладающая для всех категорий медицинских работников и устойчивая во времени роль справедливости в оплате труда в качестве определяюшего стимула. Показано, что все выявленные признаки феномена справедливости в оплате труда увязываются с ее консервативной функцией по отношению к показателям трудового поведения и планируемым организационным инновациям.

Ключевые слова: социальная справедливость, справедливость в оплате труда, патерналистская и либеральная модели справедливости, реализация справедливости, эффективный контракт, медицинские работники, врачи

Время показало, что уйти от проблемы справедливости при решении общих и частных задач, связанных как с переустройством общества в целом, так и с решением проблем оплаты труда в отдельной организации, невозможно. Понятие справедливости стало бы лишним только в мире с неограниченными ресурсами или в утопиях, подобных марксистской либо анархо-либеральной [Козловски 1999, с. 260]. В марксистском проекте проблема справедливости снимается за счет принципа равенства: «от каждого по способностям, каждому по потребностям», а в анархолибералистском - идеалами эффективности и свободы.

Тем не менее попытки уйти от рассмотрения принципов справедливости случаются и в реальной истории: так, на начальном этапе осуществления рыночных преобразований в России они все больше стали рассматриваться как помеха на пути радикальных реформ. Помимо этого, произошло самоустранение от анализа этих проблем и среди преобладающей части обществоведов; само это понятие практически исчезло со страниц социологической и экономической литературы. Аргументация, что нормы справедливости противоречат принципам эффективности, оказалась решающей не только для экономистов, менеджеров, но и для социологов.

Если учитывать, что в советское время акцент делался на изучение процессов выравнивания реальных доходов социальных групп, стирания различий между городом и деревней, между представителями умственного и физического труда, а справедливость ассоциировалось преимущественно с уравнительностью, то такое поведение вполне объяснимо. Уже в конце 1980-х гг. на господствующие представления об эгалитарности был обрушен небывалый шквал критики, а в начале 1990-х гг. справедливость стала рассматриваться как пережиток советского прошлого. СМИ постоянно подчеркивали, что в обществе с рыночной демократией нет места социальной справедливости. Отмечая особенности отношения к справедливости в первые годы либеральных реформ, аналитики отмечают, что в гайдаровский период в России самым модным утверждением либералов было «чем больше справедливости (равенства), тем меньше темпы роста производительности труда» [Пирогов, Ефимов 2008]. По данным социологических исследований, в 1995 г. ценность справедливости занимала 10-е место [Назаров 1999]. Поэтому в работах социологов того периода если и ставилась проблема социальной справедливости, то делалось это под знаком борьбы с уравниловкой и поиском новых факторов мотивации труда [Морин 1990].

С начала 2000-х гг. обращение к этой теме заметно возросло. Это видно и по количеству публикаций по теме социальной справедливости, размещенных 
в РИНЦ. За 1992-1999 гг. понятие «социальная справедливость» в названиях журнальных статей, книг, материалов конференций, диссертаций встречалось 28 раз, в 2001-2009 гг. - 256, а в 2010-2015 гг. - 541 раз. Для сравнения: термин «рыночная эффективность» упоминался за указанные периоды 130, 302, 240 раз соответственно. Почти двадцатикратная динамика роста обращения отечественных ученых к проблеме социальной справедливости и лишь двукратная к теме рыночной эффективности говорит сама за себя.

За усиливающимся интересом к этой проблеме скрывается прежде всего факт ее растущего значения как фундаментальной ценности. Социологи фиксируют, что мечта о жизни в разумно устроенном обществе входит в число трех наиболее распространенных вариантов мечтаний «для себя» в жизни россиян $(33 \%)$, уступая первенство лишь мечте о достатке и возможности жить «не считая копейки», и имеет сопоставимые позиции с мечтой о хорошем здоровье [Мареева 2013, с. 17]. Однако, подчеркивая, что справедливость входит в число трех терминов, вызывающих наиболее позитивные чувства (52\%) наряду с порядком (58\%) и стабильностью (49\%) (по данным ВЦИОМ 2004-2009 гг.), исследователи отмечают, что мобилизационный запрос на справедливость сравнительно невысок, адресован власти, но не сопряжен с солидарностью, готовностью за нее бороться [Петухов 2011]. Завышенные ожидания россиян относительно активной роли государства в восстановлении справедливости объясняются не только чрезмерным патернализмом, но и сложившейся в стране институциональной системой. На основе обобщенных данных социологических исследований учеными делаются выводы, что в 1996-2013 гг. из-за ограниченности реальных прав и возможностей многие люди, ранее полагавшиеся на себя в решении своих проблем, стали рассчитывать именно на помощь государства [Вахтина 2014, с. 62]. Отмечается, что при отсутствии сколько-нибудь надежной поддержки со стороны работающих социальных институтов, особенно при усилении кризисной ситуации, работникам ничего не остается, как обращаться за поддержкой непосредственно к государству [Черныш 2012, с. 15].

Можно предположить, что источники роста ценности социальной справедливости следует искать прежде всего в сфере труда. К середине второго десятилетия XXI в. стало очевидно, что ожидания большей части граждан относительно возможности посредством своего труда добиться желаемого для себя жизненного результата не оправдались. Уравниловки не стало, но на смену ей пришли ощущение потери связи между размером зарплаты и личным вкладом, обиды и разочарование на фоне усилившейся поляризации бедности и богатства во время нового кризиса. В этой связи акцентирование на ценности социальной справедливости в качестве неоспоримой истины, стоящей над законом, может рассматриваться как обращение к сильному государству, способному, по мнению большинства россиян, вершить праведный суд. Выход из этой ситуации следует, на наш взгляд, искать не только в новых государственных реформах распределительной системы и ужесточении контроля над доходами верхнего среднего класса, но и в усилении связи между трудом и его достойным вознаграждением у наемных работников. Именно здесь закладываются действенные основания социальной справедливости, поскольку три четверти россиян считают справедливым, что те, кто работают быстрее и эффективнее, должны получать зарплату выше даже при формально аналогичной должности [Мареева 2013, с. 20]. 
Сложность изучения социальной справедливости во многом обусловлена ее не состоявшейся до сих пор концептуализацией в качестве идеи и теоретического объекта исследования, если не считать фундаментальной работы Дж. Ролза, малопригодной для интерпретации российской действительности. В подходах отечественных исследователей преобладающими являются оценочное отношение к понятию «социальная справедливость» и восприятие его в целостном образе как мечты и идеальной ценности. Если рассматривать в качестве объектов изучения справедливости представления о ней или проявления ее в действиях, то по степени распространенности в публикациях первое неоспоримо преобладает над вторым. Объясняется это тем, что «социальная справедливость» как понятие скорее используется для оценки состояния общества, чем для анализа конкретного поведения тех или иных субъектов [Римский 2013]. В то же время конструктивными можно назвать подходы, в которых указывается на многомерность понятия справедливости и обосновывается необходимость ввода типологии разноуровневых контекстов [Девятко 2009], выделяются макро-, мезо- и микроконтексты справедливости в трудовой деятельности работников [Черныл 2014], при этом сама проблема справедливости локализуется в деятельности организации [Гулевич 2012], она рассматривается как управляемый фактор трудовой деятельности [Бессокирная, Татарова 2014], также делаются попытки в переносе вектора анализа справедливости в сторону отдельного индивида [Шипунова 2005].

Главное, на наш взгляд, при изучении справедливости уйти от ее синкретичного видения и восприятия ее в качестве интуитивного, почти нерефлексируемого чувства. Если сейчас преимущественно предметами исследований являются оценки и понимание справедливости, то необходимо сместить акцент на определение моделей, ценностных ориентаций и мотивов поведения различных социальных групп, связанных с особенностями оценок, представлений и пониманий справедливости в тех областях деятельности и жизни, которые она затрагивает. Справедливость, как показали предыдущие исследования, - это не только вид эмоционального чувства, но и хорошая аналитическая и объясняющая переменная [Темницикий 2005].

Качественной экспериментальной площадкой для обнаружения возможностей такого подхода может стать область реформируемой заработной платы медицинских работников, в которой постоянно ощущается соприкосновение результатов труда и его вознаграждения. В сфере заработной платы можно выделять и выстраивать самые различные модели справедливости: коммунистическую, либеральную, аристократическую, патерналистскую, партнерскую, братскую (артельную) и другие. Во всех указанных моделях главенствующим является принцип уравновешивания между затратами и результатами труда. Предполагается, что в настоящее время набирает силу ориентация на патерналистскую и снижается на еще ранее востребованную либеральную модель справедливости, а остальные модели не имеют выраженного характера.

Достижение либерального равновесия, по Дж. Ролзу, - это результат соглашения о свободной сделке между добровольными торговцами, согласно которому для каждого человека наилучшим считается то, что он может достичь свободным обменом, совместимым с правами и свободами других, в преследовании собственных интересов [Ролз 1995, с. 113]. С другой стороны, патерналистское равнове- 
сие - это результат соглашения о готовности поступиться правами и свободами в обмен на защиту со стороны более сильного (государства, организации, начальника) [Темниикий 2004]. В нем предпочтительным для человека становится то, что он может достичь в результате согласования уступок, совместимых с готовностью повиноваться той власти, которой хотелось бы подчиняться. При этом в каждом конкретном случае равновесие будет нарушаться при отходе от модели желаемой наилучшей ситуации.

В определении справедливости, обращенной к личности работника, мы будем придерживаться дистрибутивной теории и ее основной нормы беспристрастности. Согласно Дж. Адамсу, эта норма воплощается в двух принципах: (1) взаимодействие рассматривается как справедливое, если исход, то есть разница между издержками и вознаграждением одного участника, равна исходу другого; (2) вознаграждение можно считать справедливым, если оно соответствует количеству затраченных усилий [Гулевич 2011, с. 48-49]. Инструментальное содержание нормы беспристрастности находит воплощение и в степени дифференциации в оплате труда однородных профессиональных групп работников, и в качестве меры соответствия между трудом и вознаграждением.

\section{Эмпирическая база исследования}

В качестве эмпирического объекта исследования рассматриваются медицинские работники бюджетных лечебных учреждений России (главные врачи, врачи, средний медицинский персонал (СМП)). В анализе были использованы материалы социологических исследований, выполненных по Программе фундаментальных исследований Национального исследовательского университета «Высшая школа экономики» в 2007-2014 гг. Все исследования проводились под руководством профессора С.В. Шишкина ${ }^{2}$. Несмотря на разное количество субъектов РФ, включаемых в выборку по годам опросов, полученные данные можно рассматривать как сопоставимые, так как постоянно обеспечивалась относительная гомогенность выборочных совокупностей медицинских работников по типу лечебных учреждений, полу, возрасту, уровню профессиональной категории, стажу работы в здравоохранении и медицинском учреждении. Во всех исследованиях данные собирались методом формализованного интервью по месту работы.

\footnotetext{
2 В 2007 и 2009 гг. опрос проводился «Левада-Центром». В 2007 г. по заказу Независимого института социальной политики в рамках исследования «Повышение оплаты труда в бюджетном секторе экономики: социальноэкономические ограничения и возможности»; объем выборки - 620 врачей в двух субъектах РФ. В 2009 г. по заказу ГУ-ВШЭ; выборка охватила 46 главных врачей, 791 врача и 761 медицинскую сестру в трех субъектах РФ. В 2011 г. опрос проведен ВЦИОМ; объем выборки составил 700 главных врачей медицинских учреждений в 34 субъектах РФ, 2450 врачей, 650 представителей среднего медицинского персонала в 20 субъектах РФ. В 2013 г. опрос проведен НИУ ВШЭ при организационной поддержке Министерства здравоохранения России в 14 субъектах РФ; объем выборки - 336 главных врачей, 1611 врачей и 1953 представителя среднего медицинского персонала. В 2014 г. опрос проводился «Левада-Центром» в четырех субъектах РФ; объем выборки - 53 главных врача, 951 врач, 547 представителей среднего медицинского персонала. Автор статьи принимал участие в разработке инструментария и анализе данных проведенных исследований.
} 


\section{Постановка проблемы}

С начала 2000-х гг. оплата труда медицинских работников неоднократно становилась объектом реформирования. Повышение оплаты труда участковым врачам и педиатрам в рамках приоритетного национального проекта в сфере здравоохранения в 2006-2007 гг., внедрение новой системы оплаты труда (НСОТ) в 2008 г. и эффективного контракта с 2012 г. - все эти меры последовательно погружают медицинских работников в орбиту денежной мотивации труда, и именно здесь формируется первое социокультурное противоречие, поскольку по условиям эффективного контракта врачам из категории государственно-ориентированных служащих (тех, кто в советское время рассматривался как транслятор патерналистской заботы государства о здоровье населения) предстоит переход в категорию наемных работников рыночного типа, устанавливающих связи с работодателем на основе индивидуальных контракт-партнерских отношений с четким указанием контролируемых показателей, за выполнение которых они могут получать стимулирующие выплаты. Сформируется ли ощущение справедливости в оплате труда по мере приближения получаемой зарплаты с учетом притязаний к ее размеру как у массовых групп наемных работников, или этого будет недостаточно с учетом представлений о статусе врача в обществе, престижности и гуманитарной роли профессии? Какими могут быть социальные последствия для общества при господстве денежной мотивации труда в сфере профессиональной деятельности медиков? Постоянным вызовом, оказывающим влияние на трудовую мотивацию, эффективность и чувство справедливости в оплате медицинских работников бюджетных лечебных учреждения, являются функционирование и развитие негосударственной медицины. Частные клиники становятся не только реальным и потенциальным местом для подработки, предпочтительным местом занятости при увольнении, но и социальным раздражителем для тех, кто хотел бы служить своей профессии без жесткой привязки к факторам денежного успеха. В этой связи возникает вопрос, как взаимосвязаны оценки справедливости в оплате труда медицинских работников бюджетных учреждений с учетом реальной и потенциальной включенности в дополнительную занятость в частных клиниках.

Эти вопросы составляют общее проблемное поле исследования. Более конкретные исследовательские задачи состоят в рассмотрении справедливости в оплате труда как аналитической переменной. Предполагается, что оценки справедливости являются не видом плохо рефлексируемого эмоционального чувства, а надежным измерителем соотношения затрат труда и его вознаграждения, они будут по-разному коррелировать с другими факторами, влияющими на размер оплаты, различными стимулами к труду и поведенческими установками, образуя синдромы патерналистской или либеральной моделей поведения.

\section{Методика измерения}

Для измерения справедливости в оплате труда использовались как прямые, так и косвенные вопросы. В исследованиях 2007 и 2009 гг. вопрос задавался напрямую: 
«Считаете ли Вы справедливой оплату Вашего труда»? Использование в исследованиях прямого вопроса столкнулось с фактом неуклонного снижения доли врачей, считающих справедливой оплату своего труда (с 16\% в 2007 г. до 6\% в 2009 г.). В 2011 г. вопрос задавался в косвенном ключе: «Какова, на Ваш взгляд, справедливая заработная плата для следующих категорий работников в тысячах рублей? (дайте оценку для медучреждений Вашего населенного пункта при условии нагрузки, при которой медицинский персонал может качественно выполнять свою работу (далее перечислялись основные должностные категории медицинских работников))». Вне зависимости от прямого либо косвенного обращения к респонденту такие конструкции вопросов всегда содержали термин «справедливость», который рассматривался как объект установки для ответа. С учетом того, что этот термин затрагивает тонкие области эмоциональных чувств личности, повышает критичность в восприятии сегодняшней реальности и тем самым способствует, как выяснилось из опросов, негативной тенденциозности в ответах, в исследованиях 2013 и 2014 гг. слово «справедливость» в конструкциях вопросов не использовалось. Определение категории справедливо оплачиваемых работников строилось по ответам на несколько независимых вопросов. Мы исходили из того, что проявления степени полноты чувства справедливости в оплате труда можно обнаружить:

1. На основе соотношения ответов на вопросы о размерах получаемой зарплаты и ожидаемой с учетом того, что размер ожидаемой зарплаты позволит сосредоточиться на выполнении своих профессиональных обязанностей на одной полной ставке. К справедливо оплачиваемым работникам были отнесены те, размер получаемой зарплаты которых равен либо больше ожидаемой.

2. По оценкам достаточности планируемого повышения заработной платы, чтобы иметь возможность сосредоточиться на выполнении своих профессиональных обязанностей и не искать дополнительную работу по внешнему совместительству. То есть, те, кто считает планируемое повышение зарплаты достаточным и соответствующим представлениям о справедливом уровне оплаты труда, оцениваются как справедливо оплачиваемые.

3. По уровню оценок соответствия зарплаты затрачиваемым усилиям и степени удовлетворенности размером заработка. К справедливо оплачиваемым работникам отнесены те, кто считают, что получаемая зарплата соответствует затрачиваемым усилиям, и при этом ими даются высокие оценки удовлетворенности ее размером.

Кроме того, во всех исследованиях использовался набор полностью повторяющихся вопросов, выступающих косвенными измерителями феномена справедливости: определение места справедливости в оплате труда среди других стимулов к труду (всего тестировалось 14 стимулов), выявление факторов, влияющих на размер оплаты труда, среди которых определялась зависимость размера оплаты труда от личного трудового вклада как индикатора дистрибутивной справедливости.

\section{Справедливость в оплате труда как определяющий стимул к труду}

Исходным пунктом обращения к анализу феномена справедливости в оплате труда медицинских работников является выявленная в повторных исследованиях глорификация роли справедливой оплаты труда по сравнению со всеми остальны- 
ми возможными стимулами к хорошей работе. Так, в 2007 г. доля врачей, указавших на определяющую роль стимула справедливой оплаты труда, составила 86\%, в 2009 г. - 88\%. При этом на следующий по значимости стимул «федеральные надбавки для всех категорий врачей» указали 57 и 54\% соответственно. Среди главных врачей, опрошенных в 2009 г., разрыв между двумя указанными стимулами оказался еще выше (94 и 39\% соответственно), среди медсестер - 89 и 45\% соответственно. Безоговорочное первенство стимула справедливой оплаты труда для медицинских работников подтвердилось и по данным исследований 2013 и 2014 гг. (90 и 92\% соответственно). Поскольку исследование в 2014 г. проводилось в конце года, в период резкого ослабления курса рубля, сказавшемся на социальном самочувствии и ответах респондентов, возьмем для рассмотрения 2013 г. как относительно спокойный и в целом весьма благополучный для медицинских работников (таблицฺа 1).

\section{Таблица 1. Иерархия стимулов к лучшей работе у различных категорий медицинских} работников (\%, по данным исследования 2013 г.)

\begin{tabular}{|c|c|c|c|c|}
\hline Стимулы & Bce & $\begin{array}{l}\text { Глав- } \\
\text { врачи }\end{array}$ & Врачи & CMII \\
\hline Справедливая оплата труда & 90 & 89 & 89 & 91 \\
\hline Наличие хорошего современного оборудования & 51 & 59 & 51 & 51 \\
\hline $\begin{array}{l}\text { Создание возможностей для профессионального роста, } \\
\text { повышения квалификации }\end{array}$ & 33 & 40 & 39 & 28 \\
\hline Предоставление врачам социальных льгот (социального пакета) & 30 & 48 & 25 & 24 \\
\hline Забота о сотрудниках и похвала со стороны руководства & 28 & 17 & 25 & 31 \\
\hline $\begin{array}{l}\text { Предоставление возможности зарабатывать столько, сколько } \\
\text { сможешь }\end{array}$ & 24 & 23 & 25 & 24 \\
\hline $\begin{array}{l}\text { Улучшение возможности для получения дополнительного } \\
\text { заработка }\end{array}$ & 19 & 15 & 15 & 21 \\
\hline Признание со стороны коллег, профессионального сообщества & 16 & 22 & 17 & 14 \\
\hline $\begin{array}{l}\text { Повышение ответственности перед пациентами } \\
\text { и их родственниками при выполнении работы }\end{array}$ & 12 & 29 & 13 & 10 \\
\hline $\begin{array}{l}\text { Публичное признание заслуг } \\
\text { (звания, награды, освещение в СМИ) }\end{array}$ & 10 & 21 & 11 & 10 \\
\hline Реальная угроза потери рабочего места & 8 & 32 & 9 & 6 \\
\hline $\begin{array}{l}\text { Расширение самостоятельности } \\
\text { в решении профессиональных задач }\end{array}$ & 7 & 14 & 9 & 6 \\
\hline Взыскательная переаттестация & 5 & 22 & 7 & 4 \\
\hline $\begin{array}{l}\text { Легализация неформальных платежей } \\
\text { (оплата услуг в конвертах) }\end{array}$ & 4 & 4 & 5 & 4 \\
\hline Количество ответивших & 3193 & 273 & 1353 & 1567 \\
\hline
\end{tabular}

Примечание: сумма процентов превышает 100\%, так как можно было выбрать до пяти вариантов ответа. 
В целом два первых наиболее значимых стимула отражают требования, направленные к государству, а третье - к менеджменту организаций. Еще две другие побудительные причины, вошедшие в пятерку наиболее значимых (предоставление социальных льгот и забота о сотрудниках), имеют патерналистское содержание, не связанное с активизацией внутренних ресурсов. Стимулы, предполагающие предоставление больших возможностей для активизации внутренних ресурсов (возможности зарабатывать столько, сколько можешь, получения дополнительного заработка), затрагивают примерно пятую часть опрошенных. Возможно, их незначительная роль связывается с большими объемами работ, с перегруженностью, на которые чаще всего ссылаются медицинские работники при раскрытии факторов неудовлетворенности в организации труда. Не в почете среди возможных стимулирующих мотивов и факторы ближайшей и внешней среды окружения (признание коллег, ответственность перед пациентами, признание в обществе, СМИ).

На периферии возможных мотиваций к лучшему труду оказались негативные для личности медицинского работника стимулы (угроза потери рабочего места, взыскательная переаттестация). Их значимость в существенно большей мере (более чем в 3 раза по сравнению с другими категориями медицинских работников) актуализируется главными врачами: по их оценкам, угроза потери рабочего места вошла в пятерку наиболее значимых стимулов. Крайне низкое значение, придаваемое врачами расширению самостоятельности в решении профессиональных задач, можно объяснить либо ее наличием, либо отсутствием запроса. На последнем месте у всех категорий оказался фактор легализации неформальных платежей, что свидетельствует о роли социальной одобряемости в ответах. Итак, какой бы мы ни взяли стимул к труду, фоном для него является абсолютно преобладающая роль справедливости в оплате труда.

Для того чтобы определить, получает ли справедливая оплата труда какое-то специфическое содержание во взаимосвязи с другими стимулами или остается равнозначным для всех фоном, были проведены корреляционный, а затем факторный анализы по данным исследования 2013 г. Всего при факторном анализе оцениваемых стимулов, выполненном по методу главных компонент с вращением Varimax, выделились четыре хорошо интерпретируемых фактора, при этом в двух из них в качестве составляющей компоненты оказалась справедливая оплата труда. Первый наиболее информативный фактор (16,6\%) показывает, как главный стимул (справедливая оплата труда), положительно коррелируя с наличием хорошего оборудования, льготами и заботой о сотрудниках, созданием возможностей для их профессионального роста, формирует синдром позитивных стимулов патерналистского содержания, повышающих роль внешних факторов и благоприятствующих работе. Его можно назвать фактором патерналистской справедливости. Второй фактор, образованный с включением в него компоненты справедливой оплаты труда (9,5\% объясненной дисперсии), подчеркивает роль внутренних резервов в активизации профессиональной деятельности. В нем самая большая факторная нагрузка связывается с предоставлением возможности зарабатывать столько, сколько сможешь, которая положительно коррелирует с появлением шанса дополнительного заработка и расширением самостоятельности в решении профессиональных задач. Его можно назвать фактором либеральной справедливости. Остальные два фактора не включали стимул справедливой оплаты труда (таблица 2). 
Таблица 2. Эмпирические модели патерналистской и либеральной справедливости на основе факторного анализа стимулов к труду (факторные нагрузки)

\begin{tabular}{|l|l|}
\hline Фактор патерналистской справедливости & Фактор либеральной справедливости \\
\hline Справедливая оплата труда $-0,702$ & Справедливая оплата труда $-0,304$ \\
\hline $\begin{array}{l}\text { Наличие хорошего современного } \\
\text { оборудования - 0,712 }\end{array}$ & $\begin{array}{l}\text { Улучшение возможности для получения } \\
\text { дополнительного заработка }-0,543\end{array}$ \\
\hline $\begin{array}{l}\text { Забота о сотрудниках и похвала } \\
\text { со стороны руководства - } 0,578\end{array}$ & $\begin{array}{l}\text { Предоставление возможности зарабатывать столько, } \\
\text { сколько сможешь - } 0,657\end{array}$ \\
\hline Предоставление врачам социальных льгот $-0,569$ & $\begin{array}{l}\text { Расширение самостоятельности } \\
\text { в решении профессиональных задач }-0,462\end{array}$ \\
\hline
\end{tabular}

Таким образом, факторный анализ стимулов к хорошей работе показал, что справедливость оплаты труда может рассматриваться не только в качестве отражения патерналистских чаяний и надежд, связываемых с обращением к государству, ведомству, организации, но и как потенциальный фактор выравнивания перспектив на достижение значимого индивидуального результата и успеха в работе. Полученный результат подтверждает гипотезу о конструктивном потенциале переменной «справедливость в оплате труда» и опровергает доводы в защиту ее равнодействующего характера.

Выявленные факторы патерналистской и либеральной моделей справедливости в оплате труда предполагают, что за ними скрываются различающиеся по своим объективным характеристикам, трудовому поведению и мотивации категории работников. Для проверки данной гипотезы на основе предварительно построенных кросс-табуляций по результатам корреляционного анализа компонент с наибольшими факторными нагрузками были вычислены две типологические категории: (1) врачи, у которых стимул справедливой оплаты труда положительно сочетается с ориентацией на предоставление хорошего современного оборудования, (2) врачи, у которых справедливая оплата как стимул положительно сочетается с предоставлением возможности зарабатывать столько, сколько сможешь. Доля первых составила примерно одну треть, а вторых - пятую часть от числа опрошенных врачей, а остальные объединились в смешанный тип. Сравнительный анализ данных типологических категорий показал, что по объективным характеристикам врачи, у которых стимул справедливой оплаты труда положительно сочетается с предоставлением возможности зарабатывать столько, сколько сможешь, по сравнению с противоположной категорией врачей, представлены в существенно большей мере мужчинами (33 против 26\%), работающими в Москве (25 против 18\%), группой высокооплачиваемых (с зарплатой более 45 тыс. руб.; 27 против 18\%). Также выявлено, что они чаще проходили обучение работе на новом оборудовании (40 против $33 \%$; в организации оплаты труда таких врачей в большей мере не устраивает несоответствие заработка уровню квалификации (48 против 38\%) и объему выполняемой работы (74 против 65\%). Вместе с тем они с большим сомнением оценивают возможность определить критерии качества выполняемой работы (67 против 76\%), в меньшей мере придерживаются позиции, что в ходе реформы оплаты труда базовая часть должна расти быстрее в течение всего периода (32 против 44\%). 
Таким образом, выявлено, что стимул справедливой оплаты труда может положительно коррелировать с другими разнонаправленными по содержанию стимулами к хорошей работе. При ее положительном сочетании с признаками внутренних резервов в активизации профессиональной деятельности (предоставлением возможности зарабатывать столько, сколько сможешь) мы выходим на категории врачей с большим ресурсным потенциалом и конструктивно критической позицией в отношении значимых сторон труда. В такой комбинации справедливость может рассматриваться как инструментальное средство обеспечения условий для хорошего заработка и носит либертаристский характер. Положительное сочетание стимула справедливой оплаты труда с обеспечением современным оборудованием, льготами и заботой о сотрудниках предполагает, на наш взгляд, объяснение справедливости как средства получения равных для всех условий улучшения профессиональной деятельности и носит эгалитаристский характер.

\section{Справедливость как результат соотношения между притязаниями к зарплате и ее реального размера}

На фоне явной динамики роста зарплаты врачей стал заметным феномен постепенного снижения притязаний к ее размеру (таблища 3). В измерении уровней притязаний можно утверждать об умеренности таковых, если превышение ожидаемого размера зарплаты ${ }^{3}$ над получаемым не превышает трех раз, поскольку «по оценкам НИУ ВШЭ, средняя заработная плата врачей должна увеличиться в 2018 г. в 2,9 раза в номинальном выражении по сравнению с 2012 г., а зарплата среднего медицинского персонала - в 2,5 раза» [Шишкин, Темницкий, Чирикова 2013, с. 32]. То есть понятие ожидаемой зарплаты соотносится нами с положением эффективного контракта, в рамках которого размер зарплаты позволяет сосредоточиться на выполнении своих профессиональных обязанностей по одной полной ставке. Соответственно, под завышенными притязаниями к размеру зарплаты подразумевались размеры, превышающие получаемую зарплату более чем в три раза. Кроме того, отдельно стоит выделить непритязательных к заработку медицинских работников, ожидаемая зарплата которых равна либо меньше получаемого заработка.

Анализ динамики соотношения ожидаемой зарплаты и ее реального размера показал явное доминирование умеренности в притязаниях медицинских работников. Доля врачей, финансовые ожидания которых к размеру зарплаты не превышали двух раз по сравнению с получаемой, возросла за годы наблюдений с $29 \%$ в 2007 г. до 46\% в 2013 г., но в 2014 г., в кризисной ситуации, вновь снизилась. Также выяснилось, что за завышенными притязаниями скрываются

\footnotetext{
3 Для выявления притязаний к ожидаемой зарплате в исследованиях 2011, 2013, 2014 гг. использовалась формулировка анкетного вопроса: «Как Вы считаете, какой уровень заработной платы по основному месту работы должен получать сегодня врач (в анкете среднего медицинского персонала - медсестра), чтобы иметь возможность сосредоточиться на выполнении своих профессиональных обязанностей на одной полной ставке (тыс. руб.)?». В исследованиях 2007 и 2009 гг. вопрос звучал: «Исходя из Вашей специальности, квалификации, условий труда, с учетом опыта работы, какой заработок в среднем за месяц Вы считали бы для себя нормальным (достойным) при работе на полную ставку (тыс.руб.)?».
} 
преимущественно мотивы решения проблем, связанных с адаптацией к новым условиям жизни, и они обусловлены прежде всего дефицитом совокупного семейного дохода.

Таблица 3. Превышение размеров ожидаемой зарплаты по отношению к размеру получаемой зарплаты среди врачей (\%)

\begin{tabular}{|l|c|c|c|c|c|}
\hline \multirow{2}{*}{ Превышение } & \multicolumn{5}{|c|}{ Годы опроса } \\
\cline { 2 - 6 } & $\mathbf{2 0 0 7}$ & $\mathbf{2 0 0 9}$ & $\mathbf{2 0 1 1}$ & $\mathbf{2 0 1 3}$ & $\mathbf{2 0 1 4}$ \\
\hline$\leq$ получаемой & 3 & 2 & 8 & 2 & 0 \\
\hline От 1,1 до 2 & 29 & 26 & 37 & 46 & 33 \\
\hline От 2,1 до 3 & 27 & 25 & 24 & 30 & 32 \\
\hline От 3,1 до 4 & 14 & 16 & 12 & 13 & 18 \\
\hline От 4,1 до 5 & 9 & 12 & 8 & 4 & 7 \\
\hline От 5,1 и выше & 18 & 19 & 11 & 5 & 10 \\
\hline Количество ответивших & $\mathbf{6 2 1}$ & $\mathbf{7 5 6}$ & $\mathbf{2 0 5 3}$ & $\mathbf{1 3 7 2}$ & $\mathbf{8 3 8}$ \\
\hline
\end{tabular}

Было установлено, что за крайней умеренностью (случаями, когда размер ожидаемой зарплаты равен либо даже меньше получаемой) в притязаниях к ожидаемой зарплате кроется не аскетизм и непритязательность врачей, а результат реального воплощения ожиданий к приемлемому уровню оплаты труда. Наиболее наглядным это оказалось при анализе данных исследования 2011 г., в котором были выявлены достаточно наполненные для статистического анализа группы медицинских работников с равенством размеров получаемой и ожидаемой зарплат. Так, среди московских врачей в случаях указанного равенства средний размер заработной платы составил 60,5 тыс. руб., в Краснодарском крае - 53,4 тыс. руб., в Тюменской и Самарской областях - 53,6 тыс. руб. Во всех других случаях дифференциации данной категории врачей (по типу лечебного учреждения или уровню профессиональной категории) равенство получаемой и ожидаемой оплаты труда соотносилось с размером получаемой зарплаты, существенно (почти в 2 раза) превышающей среднюю зарплату по всей выборке. Указанная тенденция была воспроизведена и по данным исследования 2013 г., хотя доля данной категории врачей оказалась крайне незначительной (2\%). Установленное равенство размеров получаемых и ожидаемых зарплат можно рассматривать как количественное отражение адекватности меры труда мере вознаграждения и интерпретировать как идеальное воплощение справедливости в оплате труда. В управленческой деятельности такое соотношение может рассматриваться в качестве одного из ориентиров в построении реформы оплаты труда медицинских работников.

Из содержательного анализа выяснилось, что справедливо оплачиваемые врачи отличаются от своих коллег, завышающих уровень притязаний к размеру зарплаты, более высоким весом, придаваемым ценностям профессионального роста, 
признанию достижений со стороны коллег и близким кругом друзей и семьи, повышению социального статуса врачей в обществе. Они существенно чаще остальных считают профессию врача престижной, в большей мере удовлетворены своей работой и семейным доходом, но не готовы работать лучше, поскольку в абсолютном большинстве $(70 \%)$ считают, что они работают на высоком уровне качества и результативности.

Следует отметить, что существенных расхождений в оценках справедливости в оплате труда в зависимости от региональной принадлежности выявить не удалось. Наиболее очевидная гипотеза, что медицинские работники Москвы, размер зарплаты которых существенно выше, чем у коллег из регионов, будут демонстрировать более высокий уровень наличия справедливости в оплате и более высокие притязания к ожидаемой зарплате, не оправдалась. По данным исследования 2013 г., в котором участвовали наибольшее количество регионов (14), значимые различия (по критерию множественного сравнения Тамхейна) были обнаружены только по отношению к медицинским сотрудникам из республики Калмыкия, при этом у медиков практически всех регионов (за исключением Республики Тыва) они были существенно выше. Притязания к ожидаемому размеру зарплаты, напротив, оказались выше у медицинских работников менее экономически благополучных регионов (Калмыкия, Марий Эл, Ставропольский край), однако эти различия не являются статистически значимыми. В целом этот феномен указывает на консервативную роль справедливости в оплате труда, связываемую с представлениями о хорошей зарплате и благоустроенной жизни, значение которых подчеркивал М. Вебер при характеристике традиционного типа отношения к труду польского крестьянина [Вебер 1990, с. 81]: при достижении достаточного для хорошей жизни заработка при нормальных условиях труда работник будет делаться все, чтобы это положение закрепить, но к повышению интенсивности и качества своего труда он стремиться не будет.

Таблица 4. Представления о размерах справедливой оплаты труда разных категорий медицинских работников по оценкам главных врачей, врачей и среднего медицинского персонала (средние значения в тыс. руб., данные 2011 г.)

\begin{tabular}{|l|c|c|c|}
\hline $\begin{array}{l}\text { Считают оплату } \\
\text { справедливой для }\end{array}$ & Главврачи & Врачи & Средний медперсонал \\
\hline главных врачей & 92,7 & 105,4 & 74,1 \\
\hline заведующих отделением & 61,6 & 71,4 & 56,7 \\
\hline опытных врачей & 50,4 & 57,8 & 47,9 \\
\hline молодых врачей & 31,7 & 34,5 & 32,2 \\
\hline среднего медперсонала & 24,7 & 25,2 & 29,2 \\
\hline младшего медперсонала & 16,1 & 18,1 & 15,4 \\
\hline
\end{tabular}

Консервативную роль справедливости подтверждает еще одно обнаруженное в исследовании обстоятельство. Анализ ответов главных врачей, врачей и среднего 
медицинского персонала на косвенный вопрос «Какова, на Ваш взгляд, справедливая заработная плата для различных категорий медицинских работников?» (этот вопрос задавался только в исследовании 2011 г.) позволяет утверждать о вербальном воспроизводстве в медицинской среде института статусной иерархичности. Его проявление заключается в том, что ни у одной из выделенных групп притязания к размерам справедливого заработка не оказались выше по сравнению с другими, более высокостатусными, группами (таблиц̧а 4).

Как видно из таблицьь 4, по мере снижения статуса происходит и уменьшение притязаний к размеру справедливой оплаты труда. Эта тенденция характерна для всех анализируемых должностных и статусных категорий медицинских работников. Примечательно, что оценки главных врачей выглядят более уравновешенными и строгими как в отношении своей, так и других выделяемых категорий. С другой стороны, у врачей проявляется закономерность увеличения справедливого размера как своей оплаты, так и оплаты главных врачей и опытных врачей. В целом выявленные закономерности подчеркивают устойчивый консерватизм в позициях российских медицинских работников. Обнаруженные свойства в какой-то мере являются эмпирическим подтверждением теории С.Г. Кордонского о воспроизводстве в советское и настоящее время сословного устройства общественной жизни: справедливость, понимаемая как совокупность устойчивых представлений о равенстве в аристотелевском смысле, выполняет при таком подходе роль ценностных оснований [Кордонский, Дехант, Моляренко 2012]. Применительно к управленческой практике выявленные закономерности, на наш взгляд, означают, что при установлении надбавок за личные достижения, высокие результаты в работе принцип соблюдения статусной иерархичности не позволит эффективному, но занимающему низкую должность работнику получать больше по сравнению с менее эффективным, но работающим на более высокой должности, причем этот факт будет благосклонно восприниматься как самими работниками, так и их руководителями.

\section{Уровень реализации справедливости в оплате труда по оценкам реальных ситуаций в труде}

Фиксация полного равенства размеров получаемой и ожидаемой зарплаты как идеального воплощения справедливости в оплате труда является, как мы выяснили, редким случаем и, скорее, может рассматриваться как идеальнылй тип, чем отображение действительности. Более приближенными к реальным производственным ситуациям способны стать оценки справедливости на основе соотношения ответов на вопросы о степени соответствия размера зарплаты затрачиваемым усилиям и об уровне удовлетворенности размером зарплаты. Согласованные ответы на данные вопросы (измеряемые по полностью упорядоченной пятибалльной шкале) могут рассматриваться как индикаторы полноты реализации справедливости в оплате труда. Предполагается, что о максимальной степени справедливости оплаты будут свидетельствовать оценки «5» уровня соответствия размера зарплаты затрачиваемым усилиям при высоком (на «5») уровне удовлетворенности размером заработной платы. Предварительно было выявлено, что между ответами на указанные 
вопросы существует высокая положительная корреляция, характерная для всех категорий медицинских работников и устойчиво подтверждаемая данными исследований 2013 и 2014 гг. (таблиц̧а 5).

Таблица 5. Уровни соответствия размера зарплаты затрачиваемым усилиям и удовлетворенности размером заработной платы у различных должностных категорий медицинских работников в зависимости от года опроса (средние значения, минимум - 1, максимум - 5)

\begin{tabular}{|l|c|c|c|c|c|c|}
\hline \multirow{2}{*}{} & \multicolumn{6}{|c|}{ Годы опроса } \\
\cline { 2 - 7 } & \multicolumn{3}{|c|}{2013} & \multicolumn{3}{c|}{2014} \\
\cline { 2 - 7 } & Главврачи & Врачи & СМП & Главврачи & Врачи & СМІ \\
\hline $\begin{array}{l}\text { 1. Средний балл соответ- } \\
\text { ствия зарплаты усилиям }\end{array}$ & 3,10 & 2,66 & 2,51 & 3,09 & 2,04 & 1,98 \\
\hline $\begin{array}{l}\text { 2. Средний уровень } \\
\text { удовлетворенности } \\
\text { размером зарплаты }\end{array}$ & 3,45 & 2,83 & 2,66 & 3,34 & 2,15 & 2,02 \\
\hline $\begin{array}{l}\text { Корреляция между 1 и 2 } \\
\text { коэффициент Пирсона) }\end{array}$ & 0,624 & 0,582 & 0,594 & 0,746 & 0,697 & 0,679 \\
\hline
\end{tabular}

Установленный факт последовательного повышения уровня удовлетворенности размером заработной платы по мере роста уверенности в том, что размер зарплаты соответствует затрачиваемым усилиям, следует рассматривать как надежный субъективный показатель степени насыщения справедливости в оплате труда. В отличие от показателя справедливости, основанного на соотношении получаемого и ожидаемого размеров зарплаты, он оказался более чувствительным к изменениям в социально-экономической ситуации и принадлежности к должностным категориям.

Начавшийся в конце 2014 г. кризис сопровождался понижением оценок соответствия зарплаты затрачиваемым усилиям и удовлетворенности размером зарплаты у всех должностных категорий медицинских работников. Причем у врачей и представителей среднего медицинского персонала этот регресс оказался более заметным по сравнению с ситуацией с главными врачами. По обоим годам исследований проявляется одна и та же тенденция: с ухудшением должностного статуса снижаются и оценки соответствия зарплаты затрачиваемым усилиям и удовлетворенности размером зарплаты.

Представляется актуальным сравнительный целевой анализ врачей, оценивших по максимуму (на «5») соответствие зарплаты затрачиваемым усилиям и удовлетворенность ее размером (доля которых по данным 2013 г. составила 5\% от числа опрошенных) с другими возможными типологическими категориями.

Насколько конструктивной является данная связь? Способствует ли она большей интенсивности и качеству труда или отражает наивысший достигнутый результат и желание его удержать? Ответы на эти вопросы может дать таблица 6. 
Таблица 6. Размеры получаемой и ожидаемой зарплат врачей, оценки уровня качества и результативности в работе в зависимости от характера соотношения оценок зарплаты затрачиваемым усилиям и удовлетворенности размером заработка (по данным 2013 г.)

\begin{tabular}{|l|c|c|c|}
\hline $\begin{array}{l}\text { Характер соотношения } \\
\text { оценок зарплаты } \\
\text { затрачиваемым } \\
\text { усилиям и удовлетво- } \\
\text { ренности заработком }\end{array}$ & $\begin{array}{c}\text { Размер получаемой } \\
\text { зарплаты } \\
\text { (в среднем тыс. руб.) }\end{array}$ & $\begin{array}{c}\text { Размер ожкидаемой } \\
\text { зарплаты } \\
\text { (в среднем тыс. руб.) }\end{array}$ & $\begin{array}{c}\text { Работают на высоком } \\
\text { уровне качеста } \\
\text { и результативности } \\
\text { (\%) }\end{array}$ \\
\hline $\begin{array}{l}\text { Совсем «нет» тем } \\
\text { и другим (n=229 чел.) }\end{array}$ & 23,7 & 77,7 & 61 \\
\hline $\begin{array}{l}\text { На «2» тем и другим } \\
\text { (n=93 чел.) }\end{array}$ & 30,4 & 77,0 & 58 \\
\hline $\begin{array}{l}\text { На «3» тем и другим } \\
\text { (n=257 чел.) }\end{array}$ & 35,6 & 77,9 & 61 \\
\hline $\begin{array}{l}\text { На «4» тем и другим } \\
\text { (n=129 чел.) }\end{array}$ & 38,9 & 66,2 & 62 \\
\hline $\begin{array}{l}\text { Полностью «да» тем } \\
\text { и другим (п=82 чел.) }\end{array}$ & 41,9 & 69,1 & \\
\hline
\end{tabular}

При полном соответствии оценок зарплаты затрачиваемым усилиям и одновременно максимальном уровне удовлетворенности заработком размер получаемой зарплаты оказывается почти на 10 тыс. руб. выше, чем в среднем по выборке, при этом притязания к ожидаемой зарплате заметно ниже (на 6 тыс. руб. в среднем по выборке). Полученные данные могут рассматриваться как указание на результат относительного насыщения представлений о справедливости в оплате труда. Очевидно, что оно наступает, если работники по максимуму оценивают соответствие размера заработной платы затрачиваемым усилиям, и наряду с этим они также полностью удовлетворены размером получаемой зарплаты. Характерно, что абсолютное большинство таких врачей (82\%) считает, что в настоящее время они трудятся с максимально возможным уровнем качества и результативности труда, и только 2\% полагают, что могли бы работать гораздо лучше. При этом фактическая продолжительность их рабочей недели оказалась почти на 3 часа меньше, чем у других выделенных категорий врачей. Также выяснилось, что они более позитивно оценивают все тестируемые характеристики рабочего места и выполняемой работы (расположенность к месту жительства, график рабочего времени, перспективность для карьерного роста, надежность занятости, оснащенность новым оборудованием), но наиболее значимо, как и следовало ожидать, возможности рабочего места для хорошего заработка. Отличительными признаками данной типологической категории врачей являются высокие значения, придаваемые таким факторам зависимости размера заработной платы, как конечные результаты работы медицинской организации в целом (4,7 по пятибалльной шкале

4 Последовательно отбирались группы врачей, которые оценивали соответствие зарплаты затрачиваемым усилиям на «5» и удовлетворенность заработком на «5», затем на «4», «3», «2», «1» по указанным переменным. 
при 3,6 по выборке), конечные результаты работы подразделения (4,6 и 3,5 соответственно), личный трудовой вклад ( 4,6 и 3,2 соответственно), объем выполняемой работы (4,5 и 3,6 соответственно). В целом это врачи, довольные своей работой, ее возможностями для жизни и профессиональной состоятельности; их доля составила $5 \%$ от общего числа опрошенных. Как выяснилось, такие врачи почти в 2 раза чаще, чем в среднем по выборке, считают свою профессию престижной (56 против 29\% по выборке), и абсолютное большинство из них не готово ни при каких условиях сменить нынешнюю работу на другую, вне системы здравоохранения (96 против 70\% по выборке). Дополнительным моментом, раскрывающим особенности трудового поведения врачей, которых для краткости можно назвать довольными и, является занятость на полную ставку вместе с нежеланием иметь дополнительную оплачиваемую работу вне своего учреждения (72 против 47\% по выборке). Из числа объективных характеристик, отличающих довольных врачей от всех остальных, наиболее значимо выделяются больший стаж работы по всем показателям: в здравоохранении, в данной медицинской организации, на занимаемой должности, а также более старший возраст (в среднем 48 лет против 45 лет по выборке); среди них также больше мужчин (37 против 30\% по выборке). Между тем не выявлено значимых связей с региональной принадлежностью, видом лечебного учреждения и уровнем профессиональной категории. Таким образом, при установлении максимальной степени справедливости в оплате труда по косвенным оценочным показателям мы сталкиваемся с феноменом категории довольных врачей, демонстрирующих вполне устраивающий их статус занятости, не склонных к дополнительной трудовой активности. В этой связи становится актуальным поиск достижительного потенциала справедливости в оплате труда.

\section{Внутренние и внешние по отношению к личным усилиям факторы оплаты труда во взаимосвязи с оценками ее справедливости}

Из всего многообразия факторов, оказывающих влияние на размер заработной платы, были выделены и диагностировались те, которые могут быть непосредственно связаны с выполняемой работой и зависеть от личных усилий (достигнутой квалификации, качества работы, количества принятых пациентов или объема выполняемой работы, оценки личного трудового вклада в целом); их можно назвать факторами зарплаты посредством личных достижений в труде. В противовес первым были выделены и внешние факторы зарплаты, которые не зависели от усилий работника (результаты работы подразделения, учреждения в целом, отношение руководителя). Предполагалось, что и размер заработной платы, и оценки справедливости в оплате труда будут выше, если работник в большей мере чувствует связь с факторами личных достижений в труде. Было установлено, что указание на большую значимость зависимости размера зарплаты от уровня квалификации и оценок личного трудового вклада сопровождается более высокой заработной платой по сравнению с другими факторами, и наиболее выразительными эти диспропорции оказались у врачей. Также заметными представляются различия во взаимосвязи оценок справедливости в оплате труда с факторами, влияющими на размер зарплаты (таблица 7). 
Таблица 7. Связь между оценками справедливости в оплате труда и факторами, влияющими на размер заработной платы по оценкам врачей (коэффициент парной корреляции Спирмана при $\mathbf{p} \leq \mathbf{0 , 0 1 )}$

\begin{tabular}{|l|c|c|c|c|}
\hline \multirow{2}{*}{$\begin{array}{l}\text { Факторы, влияющие } \\
\text { на размер заработной платы }\end{array}$} & \multicolumn{4}{|c|}{ Годы опроса } \\
\cline { 2 - 5 } & 2007 & 2009 & 2013 & 2014 \\
\hline $\begin{array}{l}\text { Объем выполняемой работы, количество } \\
\text { пациентов }\end{array}$ & 0,412 & 0,316 & 0,303 & 0,227 \\
\hline Личный трудовой вклад & 0,385 & 0,369 & 0,316 & 0,204 \\
\hline Квалификация & 0,291 & 0,291 & 0,244 & 0,126 \\
\hline $\begin{array}{l}\text { Конечные результаты работы отделения, } \\
\text { подразделения }\end{array}$ & 0,322 & 0,297 & 0,317 & 0,153 \\
\hline $\begin{array}{l}\text { Конечные результаты работы учреждения } \\
\text { в целом }\end{array}$ & 0,305 & 0,325 & 0,354 & 0,169 \\
\hline Отношения с руководством & 0,218 & нет связи & нет связи & нет связи \\
\hline
\end{tabular}

Положительные корреляции справедливости в оплате труда с оценками врачей факторов, от которых может зависеть размер их зарплаты, была обнаружена по отношению ко всем диагностируемым показателям за исключением отношений с руководством, что указывает на высокую роль профессиональных качеств и достоинства врачей.

Обнаруженные связи сохранялись на среднем уровне вплоть до 2014 г. В кризисный год, по данным исследования, были утрачены либо стали менее заметными многие ранее выявленные тенденции, связи и отношения. Хотя корреляция справедливости оплаты с оценками личного трудового вклада по сравнению с оценками конечных результатов работы учреждения и снизилась к 2014 г., но оставалась все же существенной (коэффициент Спирмана 0,204 и 0,169). Сохранились и различия размеров зарплаты врачей в зависимости от факта этой связи: при обнаружении связи между оценками справедливости оплаты и зависимостью ее размера от личного трудового вклада получаемая зарплата оказалась выше в среднем на 21 тыс. руб. по сравнению с теми, у кого данная связь не выражена. Выявленные эмпирические факты указывают на первостепенность ощущения зависимости справедливости в оплате труда от оценок личного трудового вклада.

В исследованиях 2007 и 2009 гг, когда вопросы о справедливости в оплате труда задавались напрямую, факторный анализ по методу Varimax позволил обнаружить конструктивную роль справедливости в образовании новых факторов. Она проявлялась в том, что оценки справедливости оплаты труда образовывали фактор на основе положительных корреляций с оценками зависимости размера оплаты труда от квалификации и личного трудового вклада, и ему противостоял фактор, образованный на основе корреляция зависимости размера зарплаты от результатов работы подразделения и учреждения в целом, а также отношений с руководством.

Обнаруженные тенденции позволяют утверждать: (1) справедливость в оплате труда является хорошей аналитической переменной, обладающей потенциалом 
участия в образовании факторов; (2) справедливость создает факторы на основе корреляций с переменными, характеризующими непосредственно связь с выполняемой работой, и не образует с внешними по отношению к личности аспектами труда. В целом, положительная роль справедливости в оплате труда повышается, если работник в большей мере чувствует ее связь с результатами личных достижений в труде.

\section{Роль справедливости заработной платы в оценках внедрения эффективного контракта}

Эффективный контракт, принципиальные положения которого были зафиксированы в правительственной программе поэтапного совершенствования системы оплаты труда в государственных муниципальных учреждениях, является инструментом организационных инноваций в трудовых отношениях и предусматривает определенную направленность изменений в трудовой мотивации работников бюджетной сферы ${ }^{5}$. Предполагается, что мотивационная эффективность контракта будет зависеть от того, насколько четко удастся выработать критерии количества и качества затрачиваемого труда, учесть различия в сложности выполняемой работы, а главное, дать почувствовать работнику, что его вознаграждение является справедливым по отношению к личному трудовому вкладу и квалификации. Реальным воплощением этого контракта должна стать такая модель занятости, при которой работники, занятые на одной полной ставке по основному месту работы, исключили бы вторичную занятость вне своей организации.

Таблица 8. Наличие вторичной занятости у различных категорий медицинских работников (\%, давшие утвердительные ответы)

\begin{tabular}{|l|c|c|c|c|c|c|}
\hline \multirow{2}{*}{ Наличие вторичной занятости } & \multicolumn{7}{|c|}{ Годы опроса } \\
\cline { 2 - 8 } & \multicolumn{3}{|c|}{$\mathbf{2 0 1 3}$} & \multicolumn{4}{c|}{2014} \\
\cline { 2 - 8 } & $\begin{array}{c}\text { Глав- } \\
\text { врачи }\end{array}$ & Врачи & СМП & $\begin{array}{c}\text { Глав- } \\
\text { врачи }\end{array}$ & Врачи & СМП \\
\hline $\begin{array}{l}\text { В другой государственной } \\
\text { медицинской организации }\end{array}$ & 9 & 12 & 5 & 9 & 12 & 2 \\
\hline $\begin{array}{l}\text { В другой частной медицинской } \\
\text { организации }\end{array}$ & 1 & 8 & 3 & 0 & 13 & 3 \\
\hline На дому & 0 & 3 & 3 & 0 & 1 & 2 \\
\hline Вне сферы здравоохранения & 3 & 5 & 5 & 6 & 3 & 4 \\
\hline $\begin{array}{l}\text { Не имеют вторичной занятости } \\
\text { вне своей организации }\end{array}$ & 87 & 72 & 84 & 85 & 71 & 89 \\
\hline
\end{tabular}

5 Программа поэтапного совершенствования системы оплаты труда в государственных (муниципальных) учреждениях на 2012-2018 гг, утверждена распоряжением Правительства Российской Федерации 26 ноября 2012 г. N 2190-p. 
Анализ участия медицинских работников в дополнительной оплачиваемой работе вне своего учреждения в динамике 2013-2014 гг. показал, что существенных изменений не произошло. При этом доля врачей, занятых в частных медицинских организациях, не только не снизилась, но и несколько возросла (с 8 до 13\%) (таблица 8).

Выявление особенностей взаимосвязи оценок справедливости в оплате труда с отношением к вовлеченности во вторичную занятость показало почти двукратное снижение желания работать по совместительству, и наиболее явно это наблюдалось в исследованиях 2007 и 2009 гг, когда вопрос о справедливости в оплате задавался напрямую. В исследованиях 2013 и 2014 гг. при фиксировании высокого уровня соответствия размера зарплаты личным усилиям (косвенная оценка справедливости) также был заметен спад желания работать по совместительству вне своей организации, но уже не столь существенный, как в предыдущие годы исследования.

Обнаруживаемое чувство справедливости в оплате труда является фактором конформистского типа поведения медицинских работников по отношению к проводимым реформам. Так, анализ проявлений феномена справедливости в оплате труда показал, что между ответами на вопрос «Считают ли достаточным планируемое повышение заработной платы к 2018 г.?» и оценками справедливости предлагаемого повышения существует сильная положительная связь (по коэффициенту Крамера), направленность которой (по коэффициенту Лямбда) задается оценками достаточности планируемого повышения заработной платы. Наиболее явно она просматривается у врачей (таблиц̧а 9).

Таблица 9. Взаимосвязь между оценками врачами достаточности запланированного повышения зарплаты и представлениями о его справедливости (\%)

\begin{tabular}{|l|c|c|c|c|}
\hline \multirow{2}{*}{$\begin{array}{l}\text { Считают ли достаточным планируемое повышение } \\
\text { заработной платы, чтобы иметь возможность }\end{array}$} & \multicolumn{3}{|c|}{$\begin{array}{c}\text { Соответствует ли планируемое } \\
\text { повышение зарплаты представлениям } \\
\text { о справедливом уровне оплаты? }\end{array}$} \\
\cline { 2 - 5 } $\begin{array}{l}\text { профессиональных выпонении своих } \\
\text { дополнительной работы постей и не искать }\end{array}$ & \multicolumn{2}{|c|}{2013 г. } & \multicolumn{2}{|c|}{$\mathbf{2 0 1 4}$ г. } \\
\cline { 2 - 5 } & Да & Нет & Да & Нет \\
\hline Да & 72 & 28 & 85 & 15 \\
\hline Нет & 12 & 88 & 12 & 88 \\
\hline Затруднились ответить & 35 & 65 & 51 & 49 \\
\hline Количество ответивших & $\mathbf{6 8 6}$ & $\mathbf{8 7 7}$ & $\mathbf{4 6 6}$ & $\mathbf{4 7 8}$ \\
\hline Коэффициент симметричной связи Крамера & & $\mathbf{0 , 5 1 3}$ & & $\mathbf{0 , 5 8 8}$ \\
\hline
\end{tabular}

При оценках запланированного повышения зарплаты как достаточного абсолютное большинство врачей (72\%), также как и других категорий медицинских работников, считает его соответствующим представлениям о справедливом уровне оплаты труда. Предполагается, что за такого рода согласованными утверждениями 
скрывается консервативная функция справедливости оплаты труда, которая находит свои проявления в умеренности притязаний к заработной плате и условиям труда, большей удовлетворенности сторонами труда, меньшем желании что-либо менять в своей работе.

Доля врачей, подчеркивающих достаточность и справедливость запланированного повышения зарплаты (назовем их лояльнылми), составила 29\% от числа опрошенных. Как выяснилось из анализа, эти врачи получают в среднем на одну тысячу рублей меньше, чем в противоположной категории, однако их удовлетворенность ее размером оказалась существенно выше - 3,2 (в противоположной категории 2,6 балла по пятибалльной шкале). Намного чаще лояльныле врачи считают, что их зарплата соответствует затрачиваемым усилиям и успехам, достигнутым в работе (3,0 и 2,4 балла по пятибалльной шкале соответственно), при этом притязания к размеру ожидаемой зарплаты у них существенно ниже (68 и 81 тыс. руб. соответственно). Именно эти показатели свидетельствуют в пользу выдвинутой гипотезы, а ее дополнительными подтверждениями представляются данные о том, что для лояльных врачей определяющими факторами, от которых, по их оценкам, зависит размер заработной платы, в существенно большей мере, чем в противоположной категории, являются конечные результаты работы организации в целом (3,9 и 3,4 балла) и конечные результаты работы подразделения (3,8 и 3,3 балла). То есть врачи, которые подчеркивают достаточность и справедливость запланированного повышения зарплаты, придают большее значение роли организационных инструментов (конечным результатам работы организации, подразделения), чем индивидуальных (личному трудовому вкладу и квалификации) в оценках факторов зависимости размера зарплаты. Объективным подкреплением данному выводу может служить больший стаж работы в организации лояльных врачей по сравнению со всеми остальными (15,3 и 11,4 года соответственно). Занятость этой категории медработников характеризуется (по самооценкам) лучшими условиями организации рабочего места: более удобным графиком, перспективностью карьеры, наличием современного оборудования и компьютерного обеспечения. Они существенно реже, чем остальные категории врачей, имеют дополнительно оплачиваемую работу по месту основной работы, включая дежурства, внутреннее совместительство, заместительство (49 и 57\% соответственно), не столь существенно, но реже в других государственных и частных медицинских организациях. Лояльные врачи демонстрируют большую преданность своей профессиональной деятельности в здравоохранении, дают более высокие оценки престижности профессии врача (считают ее престижной 36 и 24\% соответственно). Категорию медицинских работников, согласных с достаточностью запланированного повышения зарплаты вкупе с оценками ее как соответствующей представлениям о справедливом уровне оплаты труда, следует рассматривать как надежного проводника осуществляемой в настоящее время политики реформирования оплаты труда. Вместе с тем явных отличий представителей выявленной категории от остальных врачей по каким-либо объективным признакам (полу, возрасту, профессиональной категории) обнаружить не удалось. Можно лишь утверждать, что таких врачей существенно больше в центральных районных и районных больницах (50 и 46\% соответственно) и меньше в областных больницах (17\%). Также лояльных врачей больше в Свердловской области, Красноярском крае (53 и 49\% соответственно) и меньше в Московской области и Москве (23 и $34 \%$ соответственно). 
Итак, категория лояльных врачей, отличительными признаками которых, как показал анализ, являются умеренность притязаний к заработной плате и условиям труда, большая удовлетворенность сторонами труда, преданность организации и профессии, соотносится с тем проявлениями справедливости оплаты труда, которые мы выше назвали консервативными. Поскольку вопросы о достаточности запланированного повышения заработной платы и оценки уровня ее справедливости строились по отношению к возможному будущему, то и вычлененная категория лояльных врачей, также как выявленные признаки трудового поведения и мотивации, могут раскрывать потенциал, но не реальность феномена справедливости в оплате труда.

Категория довольных врачей может рассматриваться как референтная для проводимой политики реформирования заработной платы, так как они намного чаще, чем остальные, считают, что уровень планируемого повышения заработной платы соответствует представлениям о справедливом уровне оплаты (70 и 44\% соответственно).

Итак, мы выделили три косвенных проявления чувства справедливости в оплате труда, вычислили соответствующие им типологические категории врачей (идеальные, довольные и лояльные), их долевое представительство и отличительные характеристики. В целом все эти проявления справедливости увязываются с ее консервативной функцией по отношению к показателям трудового поведения и планируемым организационным инновациям.

\section{Заключение}

Анализ возросшего в 2000-е гг. числа обращений исследователей к проблеме социальной справедливости показал, что она связывается не с ростом активности граждан России в борьбе за ее достижение, а с надеждами на помощь государства в решении жизненно важных проблем. Ареной, на которой проблема справедливости находит свое постоянное воплощение в столкновениях интересов работников и организации, является сфера заработной платы. В данном случае уже нельзя довольствоваться изучением оценок и представлений о справедливой оплате труда. Очевидно, что в центр исследовательского внимания необходимо ставить вопросы о проявлениях справедливости во взаимосвязи с мотивацией трудового поведения, условиями и организацией труда, отношением к организационным инновациям. В арсенале методов социологического измерения справедливости оплаты труда важно использовать как прямые, так и косвенные вопросы, поскольку, как показал анализ, явное преимущество одних над другими отсутствует.

Основное противоречие в решении проблемы справедливости оплаты труда применительно к медицинским работникам бюджетных лечебных учреждений видится в неопределенности их статуса. Они уже перестали быть трансляторами заботы государства о здоровье трудящихся, как это происходило в советское время, но и не являются наемными работниками рыночного типа в рамках четко прописанных контракт-партнерских отношений. Указанное противоречие проявляется в эмпирически рассчитанных моделях патерналистской и либеральной справедливости в оплате труда. То, что примерно каждый третий из числа медицинских работников связывает справедливость в оплате прежде всего с обеспечением 
оборудованием и заботой со стороны руководства, а каждый пятый - с возможностью зарабатывать столько, сколько сможешь, указывает на две выраженные тенденции в ценностном сознании медицинских работников. Первая - «только при ощущении внимания и заботы со стороны организации и государства мы будем работать лучше», вторая - «не мешайте нам зарабатывать своим профессиональным трудом; мы и больных вылечим, и себя обеспечим сами».

Однако общим, характерным для большинства медицинских работников, признаком феномена справедливости в оплате труда является его консервативное содержание. Справедливо оплачиваемые медицинские работники не готовы работать гораздо лучше, поскольку в абсолютном большинстве считают, что они в настоящее время работают на высоком уровне качества и результативности.

В притязаниях к размеру справедливого заработка ни одна из анализируемых групп медицинских работников не вышла за рамки своей статусной принадлежности, не указала на ожидаемый заработок, который (по средним значениям) превысил бы размер заработка группы, стоящей выше по статусу. Помимо этого, при осознании факта справедливости зарплаты на основной работе желание работать по совместительству в других организациях существенно снижается (почти в 2 раза). Обнаруживаемое чувство справедливости в оплате труда повышает уровень конформистского отношения к проводимым реформам (внедрению эффективного контракта), но не сопровождается стремлением увеличивать результативность труда.

Представляется, что обнаруженные свойства консервативности феномена справедливой оплаты труда медицинских работников нельзя рассматривать ни как фактор сопротивления реформам, ни как показатель адаптации к ним. Скорее, это данность, имеющая инерционно-культурные базовые принципы и обладающая, с одной стороны, механизмами сдерживания радикальных шагов в сторону возможных изменений, а с другой, конструктивными основаниями для неспешных преобразований.

\section{Литература}

Бессокирная Г.П., Татарова Г.Г. (2014) Справедливость в труде как управляемый фактор трудовой деятельности: проблемы измерения // Саралиева 3.Х. (ред.) Социальные инновации в развитии трудовых отношений и занятости в XXI. Нижний Новгород: НИСОЦ. С. $75-80$.

Вахтина М.А. (2015) Состояние легитимности институтов современной России: к вопросу о роли социальной справедливости в экономике // Мир России. № 4. С. 60-70.

Вебер М. (1990) Избранные произведения. М.: Прогресс.

Гулевич О.А. (2012) Справедливость в организации: условия и последствия // Организационная психология. Т. 2. № 1. С. 58-70.

Девятко И.Ф. (2009) О теоретических моделях, объясняющих восприятие справедливости на микро-, мезо- и макроуровнях социальной реальности // 4М. № 29. С. 10-29.

Козловски П. (1999) Принципы этической экономии. СПб.: Экономическая школа.

Кордонский С.Г., Дехант Д.К., Моляренко О.А. (2012) Сословные компоненты социальной структуры России: гипотетико-дедуктивный анализ и попытка моделирования // Мир России. № 2. С. 62-102.

Мареева С.В. (2013) Справедливое общество в представлениях россиян // Общественные науки и современность. № 5. С. 16-26.

Морин Ю.М. (1990) Социальная справедливость и оплата по труду // Социологические исследования. № 3. С. 61-64. 
Назаров М.М. (1999) Социальная справедливость: современный российский контекст // Социологические исследования. № 11. С. 41-50.

Петухов В.В. (2011) Ценностная палитра современного российского общества: «идеологическая каша или поиск новых смыслов» // МОМ. № 1. С. 6-23.

Пирогов Г.Г., Ефимов Б.А. (2008) Социальная справедливость: генезис идей // Социологические исследования. № 9. С. 3-11.

Римский В.Л. (2013) Справедливость в современной России: мечты и использование в социальных практиках // Общественные науки и современность. № 5. С. 27-36.

Ролз Дж. (1995) Теория справедливости. Новосибирск: Издательство Новосибирского университета.

Темницкий А.Л. (2004) Ориентации рабочих на патерналистские и партнерские отношения с руководством // Социологические исследования. № 6. С. 26-38.

Темницкий А.Л. (2005) Справедливость в оплате труда как ценностная ориентация и фактор трудовой мотивации // Социологические исследования. № 9. С. 81-88.

Черныш М.Ф. (2012) Миражи справедливости // Мир России. № 2. С. 103-115.

Черныш М.Ф. (2014) Справедливость заработной платы в российском контексте // Социологические исследования. № 7. С. 78-89.

Шипунова Т.В. (2005) Социальная справедливость: понятие, виды, критерии оценки // Проблемы теоретической социологии. Выпуск 5. СПб.: Астерион. С. 227-247.

Шишкин С.В., Темницкий А.Л., Чирикова А.Е. (2013) Стратегия перехода к эффективному контракту и особенности трудовой мотивации медицинских работников // Экономическая политика. № 4. С. 27-53.

\title{
The Phenomenon of Justice in the Labour Remuneration of Medical Workers
}

\author{
A. TEMNITSKY*
}

\begin{abstract}
*Alexander Temnitsky - Candidate of Science in Sociology, Associate Professor, the Sociological Department, Moscow State Institute of International Relations. Address: bldg.76, Vernadsky Av., Moscow, 119454, Russian Federation. Email: taleksandr@list.ru

Citation: Temnitsky A. (2017) The Phenomenon of Justice in the Labour Remuneration of Medical Workers. Mir Rossii, vol. 26, no 3, pp. 64-89 (in Russian). DOI: 10.17323/1811-038X-2017-26-3-64-89
\end{abstract}

\begin{abstract}
This article investigates the role of justice in labour remuneration with regard to motivation at work and the implementation of 'effective contracts' for medical workers in public healthcare institutions. The empirical data comes from surveys conducted between 2007 and 2014.

Several studies have addressed the problem of justice in the remuneration of medical workers in Russia. They show that the problem became particularly acute in 2000 s, when medical workers increasingly reported the weakening of the connection
\end{abstract}


between earnings and effort. The article introduces the notions of paternalistic and liberal models of justice in labour remuneration, and reveals those models empirically. The paternalistic model is characteristic of approximately $33 \%$ of respondents and the liberal model accounts for $20 \%$. What is highly specific to the notion of justice in the remuneration of medical workers is the contradiction between monetary motivation bolstered by 'effective contracts', on the one hand, and the social status, prestige and humanitarian role of the medical profession, on the other.

The study reveals that justice in remuneration is highly relevant for the proper incentivisation of all types of medical workers. It also shows that the correlation between earnings, effort investment and satisfaction with earnings forms a reliable index for measuring such justice.

It is shown that conservatism prevails in all of the revealed indicators of the justice phenomenon. The feeling of justice revealed in the labour payment of medical workers raises the level of conformist attitudes towards the introduction of effective contracts, but is not accompanied by an aspiration for raising the effectiveness of labour.

It is also shown that all of the indicators of the justice in the labour payment phenomenon coordinate with their conservative function towards labour behaviour indices and planned institutional innovations.

Key words: social justice, labour remuneration, paternalistic and liberal models of justice, effective contract, medical workers, doctors

\section{References}

Bessokirnaya G.P., Tatarova G.G. (2014) Spravedlivost' v trude kak upravlyaemyi faktor trudovoi deyatel'nosti: problemy izmereniya [The Justice in Work as a Manageable Work Factor: the Problems of Measurement]. Sotsial'nye innovatsii v razvitii trudovykh otnoshenii i zanyatosti $v$ XXI veke [Social Innovations in the Development of Labor Relations and Employment in the 21 st Century] (ed. Saralieva Z.H.), Nizhny Novgorod: Izdatel'stvo NISOC, pp. 75-80.

Chernysh M.F. (2012) Mirazhi spravedlivosti [Justice Mirages]. Mir Rossii, no 2, pp. 103-115.

Chernysh M.F. (2014) Spravedlivost' zarabotnoi platy v rossiiskom kontekste [The Justice of Labour Remuneration in the Russian Context]. Sotsiologicheskie issledovaniya, no 7, pp. 78-89.

Devyatko I.F.(2009) O teoreticheskikh modelyakh, ob'yasnyayushchikh vospriyatie spravedlivosti na mikro-, mezzo- i makrourovnyakh sotsial'noi real'nosti [On the Theoretical Models Explaining the Perception of Justice at Micro-, Meso- and Macro- levels of Social Reality]. $4 M$, no 29 , pp. 10-29.

Gulevich O.A. (2012) Spravedlivost'v organizatsii: usloviya i posledstviya [Justice in Organization: Conditions and Consequences]. Organizatsionnaya psikhologiya, no 1, pp. 58-70.

Kordonsky S.G., Dekkhant D.K., Molyarenko O.A. (2012) Soslovnye komponenty sotsial'noi struktury Rossii: gipotetiko-deduktivnyi analiz i popytka modelirovaniya [The Estate Components of Russia's Contemporary Social Structure: a Hypothetico-Deductive Analysis and Modeling Attempt]. Mir Rossii, no 2, pp. 62-102.

Kozlovsky P. (1999) Printsipy eticheskoi ekonomii [The Principles of Ethical Economy], SaintPetersburg: Ekonomicheskaya shkola.

Mareeva S.V. (2013) Spravedlivoe obshchestvo v predstavleniyakh rossiyan [The Fair Society in Representations of Russians]. Obshchestvennye nauki i sovremennost', no 5, pp. 16-26. 
Morin YU.M. (1990) Sotsial'naya spravedlivost' i oplata po trudu [Social Justice and Work Perceptions]. Sotsiologicheskie issledovaniya, no 3, pp. 61-64.

Nazarov M.M. (1999) Sotsial'naya spravedlivost': sovremennyi rossiiskii kontekst [Social Justice: Modern Russian Context]. Sotsiologicheskie issledovaniya, no 11, pp. 41-50.

Petukhov V.V. (2011) Tsennostnaya palitra sovremennogo rossiiskogo obshchestva: «ideologicheskaya kasha ili poisk novykh smyslov» [The Spectrum of Values in the Modern Russian Society: 'Ideological Mess or a Search of New Meanings?']. MOM, no 1, pp. 6-23.

Pirogov G.G., Efimov B.A. (2008) Sotsial'naya spravedlivost': genezis idei [Social Justice: the Origins of the Idea]. Sotsiologicheskie issledovaniya, no 9, pp. 3-11.

Rawls J.B. (1995) Teoriya spravedlivosti [The Theory of Justice], Novosibirsk: Izdatel'stvo Novosibirskogo universiteta.

Rimsky V.L. (2013) Spravedlivost'v sovremennoi Rossii: mechty i ispol'zovanie v sotsial'nykh praktikakh [Justice in Modern Russia: Dreams and Use in Social Practice]. Obshchestvennye nauki i sovremennost', no 5, pp. 27-36.

Temnitsky A.L. (2004) Orientatsii rabochikh na paternalistskie i partnerskie otnosheniya s rukovodstvom [The Orientations of Workers Towards Paternalistic and Partner Relationships with the Management]. Sotsiologicheskie issledovaniya, no 6, pp. 26-38.

Temnitsky A.L. (2005) Spravedlivost' v oplate truda kak tsennostnaya orientatsiya i faktor trudovoi motivatsii [Justice in Labour Remuneration as a Useful Orientation and a Factor of Labour Motivation]. Sotsiologicheskie issledovaniya, no 9, pp.81-88.

Shipunova T.V. (2005) Sotsial'naya spravedlivost': ponyatie, vidy, kriterii otsenki [Social Justice: Concept, Types and Evaluation Criteria]. Problemy teoreticheskoi sotsiologii, no 5, Saint-Petersburg: Asterion, pp. 227-247.

Shishkin S.V., Temnitsky A.L., Chirikova A.E. (2013) Strategiya perekhoda k effektivnomu kontraktu i osobennosti trudovoi motivatsii meditsinskikh rabotnikov [The Strategy of Transition to the Effective Contract and the Specifics of Motivation Among Health Workers]. Ekonomicheskaya politika, no 4, pp. 27-53.

Vakhtina M.A. (2015) Sostoyanie legitimnosti institutov sovremennoi Rossii: k voprosu o roli sotsial'noi spravedlivosti v ekonomike [The State of Institutional Legitimacy in Modern Russia and the Problem of Social Justice in Economics]. Mir Rossii, no 4, pp. 60-70.

Weber M. (1990) Izbrannye proizvedeniya [Selected Works], Moscow: Progress. 